\title{
10 Gbps Full Duplex Cost Effective Architecture GPON Network with Single Fiber
}

\author{
Taifoor Ul Islam ${ }^{1}$, Aftab Hussain ${ }^{2}$, Syed Shees Ashraf ${ }^{3}$ \\ ${ }^{1}$ Department of Telecommunication, Institute of Communication Technologies Islamabad, 44000, Pakistan \\ ${ }^{2}$ Department of Electrical Engineering, Swedish College of Engineering and Technology Wah Cantt, 47040, Pakistan \\ ${ }^{3}$ Department of Telecommunication, Institute of Communication Technologies Islamabad, 44000, Pakistan
}

\begin{tabular}{l} 
A R T I C L E I N F O \\
\hline Article history: \\
Received: 07 September, 2016 \\
Accepted: 08 October, 2016 \\
Online: 27 October, 2016 \\
\hline Keywords: \\
Gigabit Passive Optical Network \\
Differential Phase Shift Keying, \\
Not Return to Zero (NRZ) \\
Return to Zero \\
On-Off-keying \\
\hline
\end{tabular}

\begin{abstract}
A B S T R A C T
In this paper, a full duplex Gigabit Passive Optical Network (GPON) architecture supporting 10Gbps data transmission through single fiber cable network is proposed and demonstrated. A Non Return to Zero Differential Phase Shift Keying (NRZ-DPSK) is utilized for downstream and re-modulate the downstream signal using intensity modulator (on-off keying OOK) in Return to Zero (RZ) format in order to transmit upstream data, sustaining data rate of $10 \mathrm{Gbps} /$ channel is an optimized network in full duplex mode. Simulation results shows that uninterrupted transmission using $50 \mathrm{GHz}$ channel spacing is accomplish over a distance of $25 \mathrm{~km}$.
\end{abstract}

\section{Introduction}

A few years ago, internet traffic propensity is shifted from simple web to video based content services [1-2]. The offered copper network is not capable to support such a vast traffic this is the main motive why the complete access network is migrated to Passive Optical Network (PON) [3-4]. Future enabled and highly flexible technology to compile both wireless and wired users in well-ordered method makes PON a promising network [5] solution, provisioning high bandwidth with low CAPEX and OPEX [6].

Time Division Multiplexing-Passive Optical Network (TDMPON) may be unable to control the continuous growth of high data rate and probable demand of high bandwidth requisite in future. Wavelength Division Multiplexing-Passive Optical Network (WDM-PON) is a possible key solution for offering high data rate on users end and gives optimistic response by escalating growth or demand for broadband application [7]. A Hybrid TDM \&WDM format is advance form of PON technology [8], using centralized light source at optical line terminal (OLT) called central office

\footnotetext{
${ }^{*}$ Corresponding Author: Taifoor Ul Islam, Department of Telecommunication, Institute of Communication Technologies Islamabad, Pakistan Tel: +923339621439

Email: engr.taifoor@gmail.com

www.astesj.com
}

https://dx.doi.org/10.25046/aj010502
(CO) and re-modulate the received downstream wavelength for upstream data at optical network unit (ONU) is considered low cost accomplishment [9]. In WDM-TDM-PON different numbers of wavelengths are generated and every single wavelength is utilized on the basis of TDM among numerous ONU's [10]. For that reason, installation of this PON setup results in high resource use and put forward better bandwidth. Similarly, Differential Phase Shift Keying (DPSK) is non-coherent phase shift keying technique that provides improved transmission distance on low power resources and easier circuitry arrangement.

In previous few years different techniques with colorless full duplex transmission for both point to point and broadcast video service were proposed, but the most important weakness was the restriction of uplink data rate up to $2.5 \mathrm{Gbps}$ and by means of higher channel spacing of $100 \mathrm{GHz}[11,12]$. Similarly a network of dual fiber is accomplished of transmitting 10Gbps per channel is measured wastage of assets for both downlink and uplink [13]. A single feeder fiber architecture based on chirp-managed laser (CML) is a enhanced solution for the full duplex transmission because of its economical and petite in size. It can endure dispersion and relay back scattering [14]. This method provides transmission up to $10 \mathrm{Gbps}$ in full duplex mode. However it caused drawback of noise factor and signal distortion on the 


\section{T. Islam et al. / Advances in Science, Technology and Engineering Systems Journal Vol. 1, No. 5, 6-9 (2016)}

receiver end. The above proposed program of ref. 11, 12 and 13 use $60 \mathrm{GHz}$ of channel spacing caused definite loss of channel bandwidth. In law, channel spacing should be minimized in order to guarantee more bandwidth.

This paper is an extension of work originally presented in 2015 International Conference on Emerging Technologies (ICET) Peshawar [15]. In this proposed novel approach, we demonstrated a full duplex transmission scheme on single fiber architecture. A $10 \mathrm{Gbps}$ data signal used NRZ-DPSK pulse format in downlink, while in uplink $10 \mathrm{Gbps}$ data signal is conceded by intensity modulation (IM). This architecture saves the expenditure of second light source at ONU. Simulation results confirmed $10 \mathrm{Gbps}$ downlink data and $10 \mathrm{Gbps}$ uplink data with the channel spacing of $50 \mathrm{GHz}$. We successfully perform the transmission mutually back to back (B2B) and distance over $25 \mathrm{~km}$ with low bit error rate (BER).

\section{Working Principle and Network Architecture}

The proposed WDM-PON network architecture is shown in Figure 1.Continuous wave $(\mathrm{CW})$ lasers is used at central office to generate wavelengths from $\lambda_{1}$ to $\lambda_{4}$ for transmission. DPSK modulation is achieved by passing the light into Mach-Zender Modulator (MZM) driven by two complementary outputs of $10 \mathrm{Gbps}$ binary electrical data signal [16]. Four DPSK channels of $10 \mathrm{Gbps}$ are multiplexed and transmitted on full duplex single feeder fiber over a distance of $25 \mathrm{~km}$. On receiver side de-multiplexing is performed and each channel is going towards its nominated ONU. At ONU's half power splitters are used to deliver the data signal to the end user receiver. Whereas, the other half power signal is used to act as carrier signal for the uplink data and re-modulated by Intensity Modulation in OOK format.

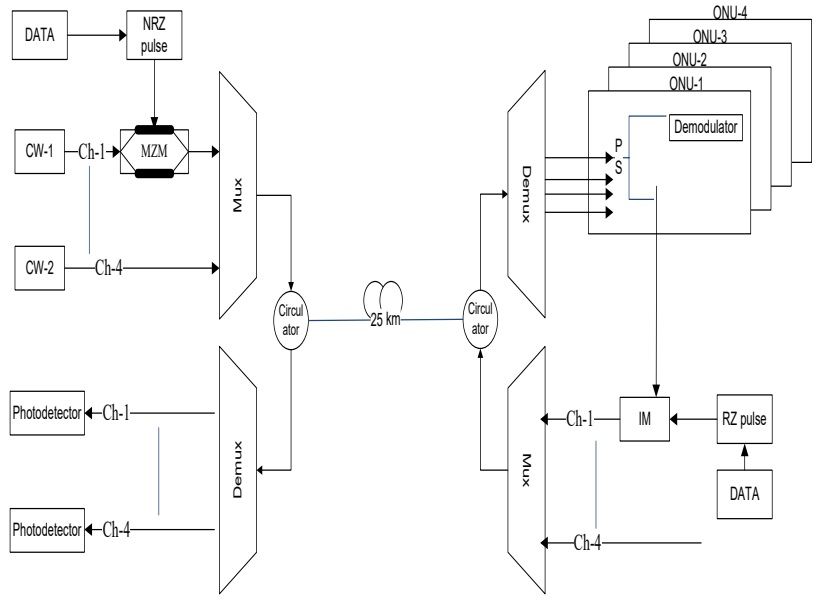

Figure 1 Schematic diagram of proposed WDM-PON Architecture

\section{Simulation Setup and Operation}

The proposed WDM-PON architecture design full duplex single feeder fiber network with four bi-directional channels of $10 \mathrm{Gbps}$ over a distance $25 \mathrm{~km}$. This model is simulated using Optisystem 7.0 as shown in Figure 2. Four continuous wave lasers are used as a centralized light source to create wavelengths at $1551.3 \mathrm{~nm}\left(\lambda_{1}\right)$, $1551.72 \mathrm{~nm}\left(\lambda_{2}\right), 1552.1 \mathrm{~nm}\left(\lambda_{3}\right)$ and $1552.53 \mathrm{~nm}\left(\lambda_{4}\right)$.Visibly evident that channel spacing is $50 \mathrm{GHz}$ with the launch power -3 $\mathrm{dBm}$ each. Four MZM are used to encode data on these channel using NRZ-DPSK format. Subsequently, four wavelengths are multiplexed by $4 \times 1$ multiplexer with a channel spacing of $50 \mathrm{GHz}$ and transmitted over $25 \mathrm{~km}$ on single feeder fiber architecture. General settings used for Single Mod Fiber (SMF) in simulation model are as follows. Attenuation coefficient $(\alpha)$ is $0.2 \mathrm{~dB} / \mathrm{km}$, core diameter $(\phi)$ is set to $80 \mu \mathrm{m} 2$ and dispersion slop is set to zero. The downlink signals are de-multiplexed at receiver side by using $1 \times 4$ de-multiplexer and forwarded to corresponding ONU. At ONU power splitter is used to tap half power for Mach-Zender Interferometer (MZDI) de-modulator before it is detected on pin receiver. The other half power is given to Mach-Zender Intensity Modulator (IM) driven by 10Gbps uplink data with RZ format. This re-modulated OOK uplink signal is transmitted back to OLT over a distance of $25 \mathrm{~km}$ on the same fiber. We used pin photo detector with the following specifications; Responsitivity (R) is $1 \mathrm{~A} / \mathrm{W}$ and dark current (ID) is $10 \mathrm{nA}$.

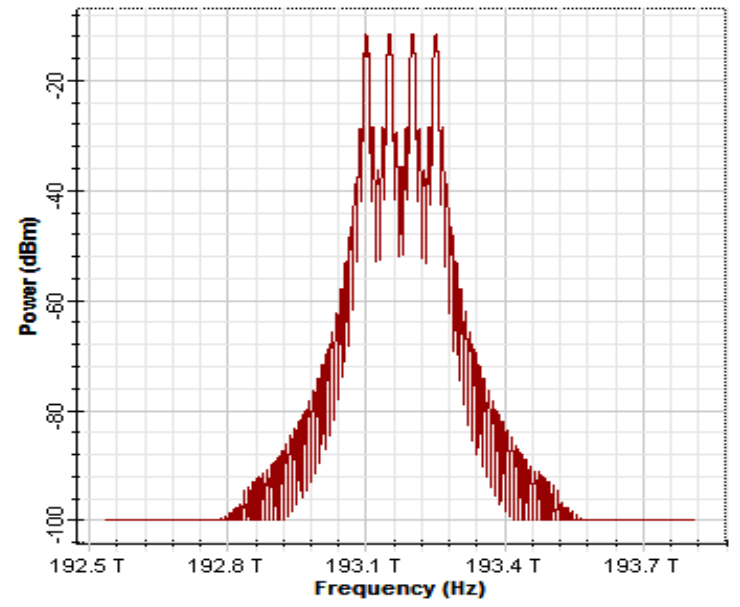

Figure 2 (a) Four downlink DPSK multiplex channels NRZ Based

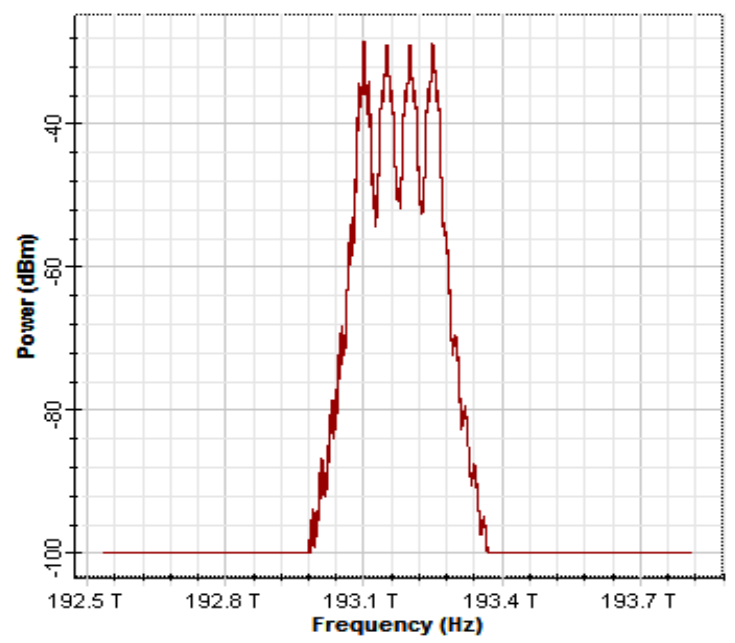

Figure 2 (b) Four downlink DPSK multiplex channels RZ based

\section{Performance analysis and results}

BER analysis and eye diagram were the main criteria to assess the performance of network. BER as function of received optical power for both uplink and downlink channels are shown in Figure 3. Optical power measured during B2B scenarios in downlink direction at $10^{-9}$ BER for channels $(1,2,3$ and 4$)$ are $-40.36 \mathrm{dBm}$, 
$-39.92 \mathrm{dBm},-38.76 \mathrm{dBm}$ and $-39.99 \mathrm{dBm}$ respectively. Similarly, optical power measured over a distance of $25 \mathrm{~km}$ for downlink channels (1, 2, 3 and 4$)$ are $-40 \mathrm{dBm},-39.9 \mathrm{dBm},-38.73 \mathrm{dBm}$ and $-39.94 \mathrm{dBm}$ respectively. The differences between each channel power at required BER $(0.01,0.01,0.03$, and 0.05$) \mathrm{dBm}$ are called transmission power penalties. Whereas, analyzing the network for OOK uplink data we only consider the $25 \mathrm{~km}$ distance values in single feeder fiber. There will no B2B values. Optical power received at required BER for channels $(1,2$ and 4$)$ at a distance of $25 \mathrm{~km}$ are $-31.88 \mathrm{dBm},-27.61 \mathrm{dBm}$ and $-28.89 \mathrm{dBm}$ respectively.

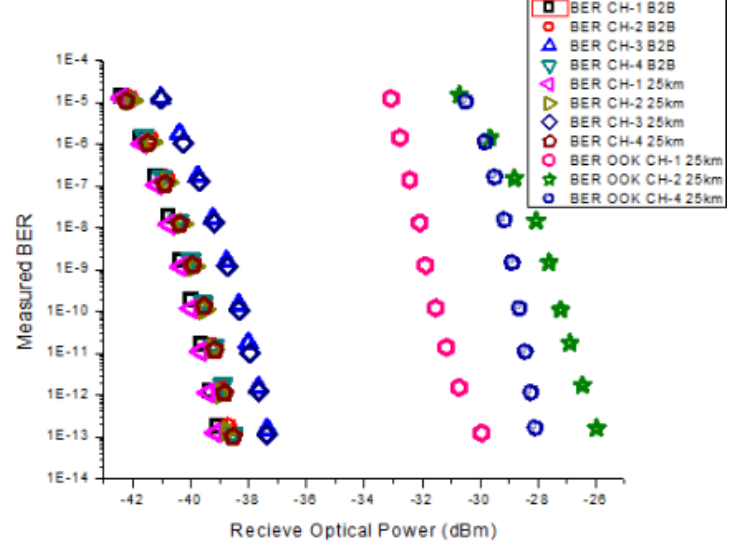

Figure 3: BER for multiplexed Downlink and Uplink both B2B and $25 \mathrm{~km}$

All DPSK downlink and OOK uplink channels over a distance of $25 \mathrm{~km}$ are shown in Figure 4. It is evident that overall network performance is good. Conversely, for better representation of network, the preferable channels are channel-1 and channel-4. As these channels exhibit better results for both downlink and uplink scenarios as compared to the rest. The average power penalty for four downlink multiplexed channels is measured about $0.1 \mathrm{dBm}$ after transmitting over $25 \mathrm{~km}$ without any signal amplifier. Figure 5 illustrates average BER for B2B and $25 \mathrm{~km}$ downlink and uplink scenarios.

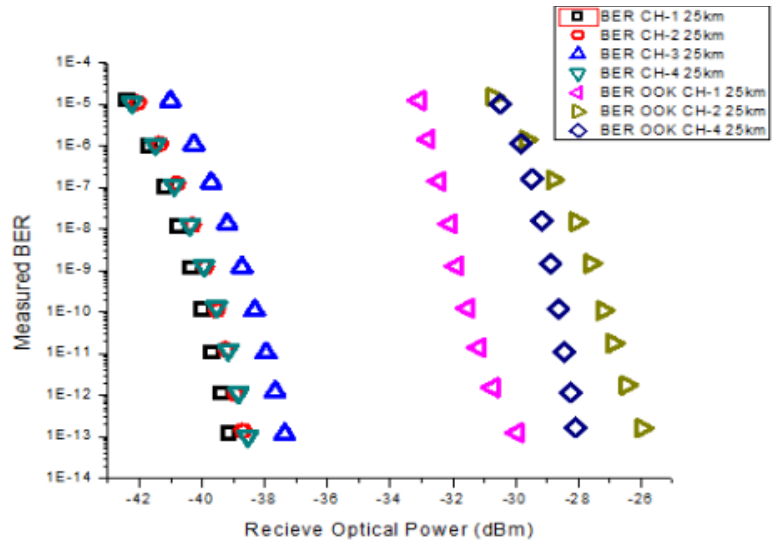

Figure 4 BER of downlink and uplink multiplexed channels for $25 \mathrm{~km}$

All four DPSK downlink channels eye diagrams are presented in Figure 6. Whereas Figure 7 is showing all feasible OOK uplink eye diagrams. These eye diagrams illustrate that error free transmission is achieved in full duplex on single feeder fiber architecture.

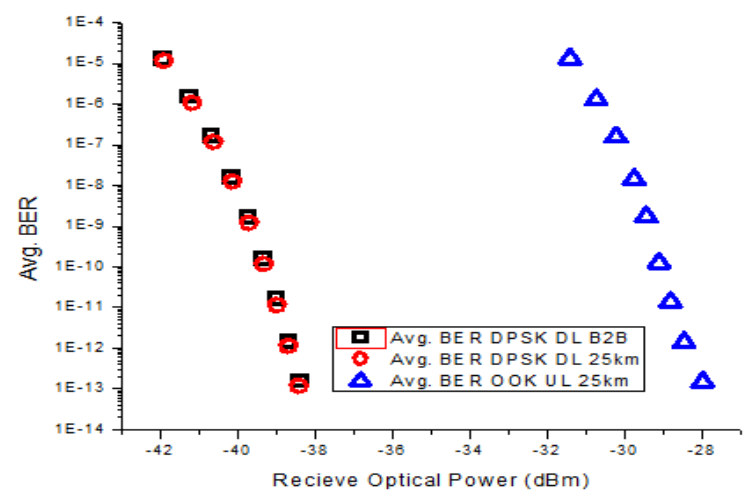

Figure 5: Average BER of DPSK DL and OOK UL over $25 \mathrm{~km}$
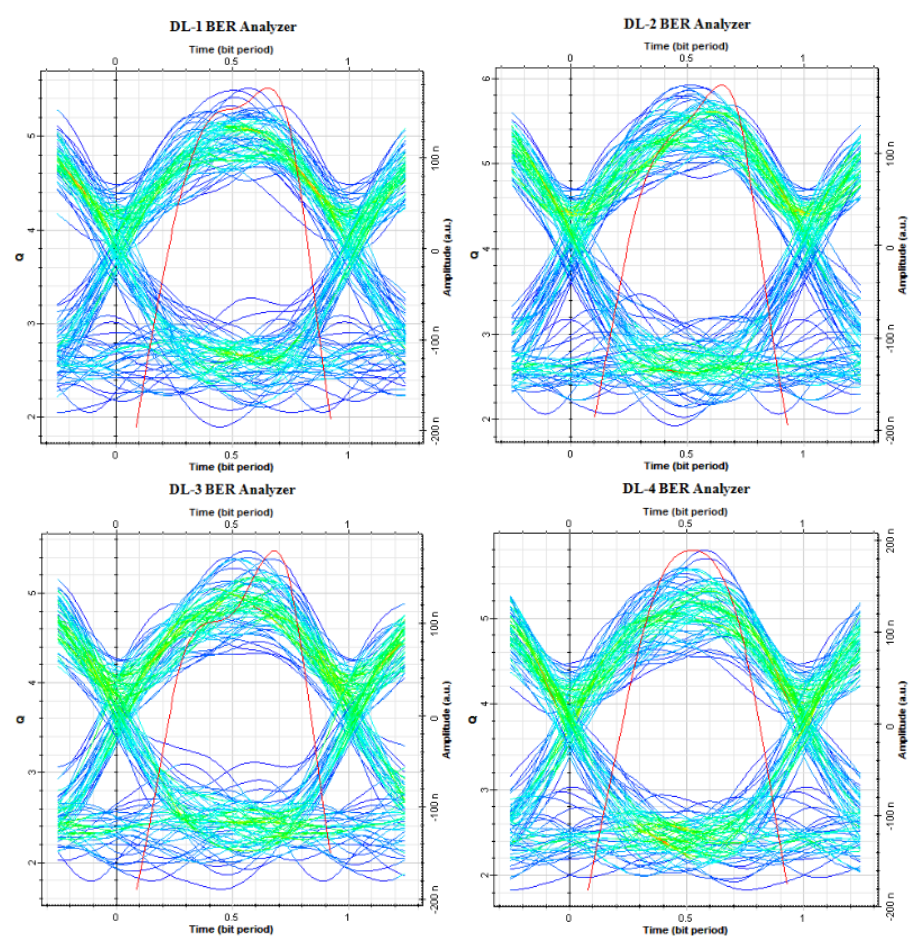

Figure 6: Eye diagrams of DL DPSK channels
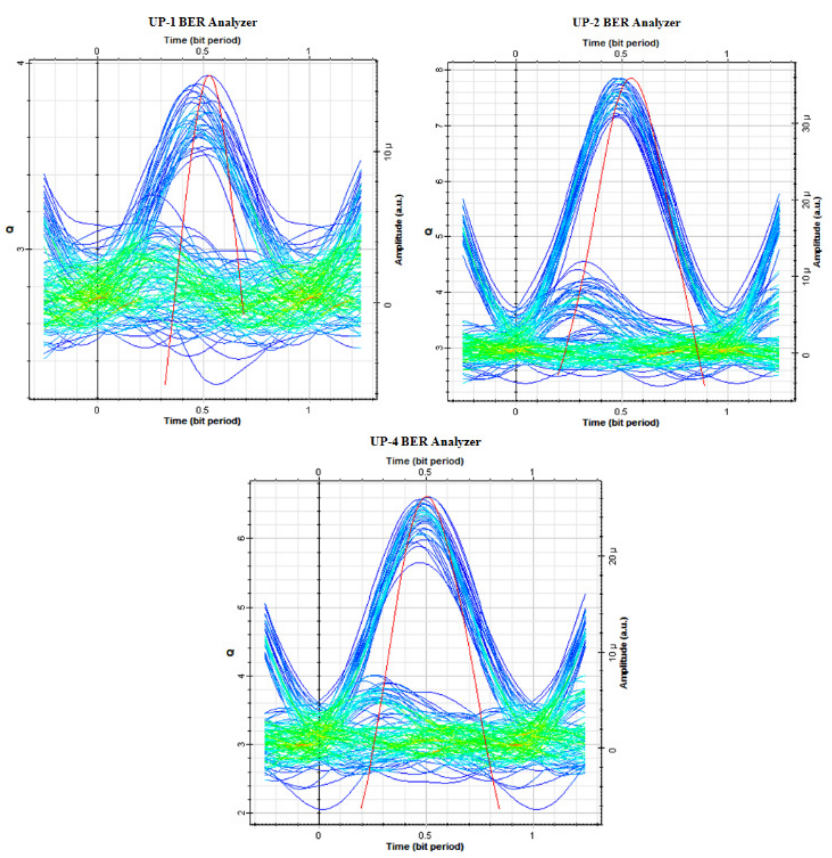

Figure 7: Eye diagram of OOK UL channels 


\section{Conclusion}

We demonstrated 10 Gbps full duplex transmission scheme carried on single fiber network architecture. Our proposed system utilized DPSK format in NRZ shape for downlink path with data rate $10 \mathrm{Gbps} / \mathrm{channel}$ and re-modulated the downlink signal using OOK in RZ shape with the same data rate for uplink path. Results showed error free cost effective bi-directional transmission effectively achieved over a distance $25 \mathrm{~km}$ with low BER without any additional signal amplifier. Moreover it is also observed that the scheme presented enhanced receiver sensitivity and saved the capital (cost of second fiber for uplink and one external modulator).

\section{References}

[1] D. M. S. Sultan and M. T. Arefin," GPON, the ltimate pertinent of next generation triple-play bandwidth resolution", J. Tel. Info. Techno. 2: 53-60 (2011)

[2] J. Quan-xin, Y. Xiao-li, X. Xiang-jun, Y. Chong-xiu, and L. Bo, “A millimeter-wave WDM-ROF system based on super continuum technique", Optoelect. Letters, 7: 440-442(2011).

[3] K. Prince, T. B. Gibbon, R. Rodes, E. Hviid, C. I. Mikkelsen, C. Neumeyr, M. Ortsiefer, E. Ronneberg, J. Rosskopf, P. Ohlen, E. In de Betou, B. Stoltz, E. Goobar, J. Olsson, R. Fletcher, C. Abbott, M. Rask, N. Plappert, G. Vollrath, and I. T. Monroy, "GigaWam next-generation WDM-PON enabling gigabit per-user data bandwidth," J. Lightwave Techno. 30: 14441454 (2012)

[4] I. Cale, A. Salihovic, M. Ivekovic, "Gigabit Passive Optical Network GPON", in Proceedings of the ITI 2007 29th International Conferece on Infomation Technology Interfaces, 679-684 (2007).

[5] A. M. Sitaram, Kadali. M. Swamy, A. R. Krishna, "Gigabit passive optical networks (GPON) the ultimate solution for large bandwidth", Int. J. Innov. Techno. Explor. Engg. 1: (51-53) 2012.

[6] W. Zahaoqing," Research on the Application of GPON Technologies", IEEE International Conferences on Multimedia and Signal Processing, 61-63 (2011).

[7] Sumanpreet, S. Dewra, "A review on gigabit passive optical network (GPON)", Int. J. Adv. Res. Comp. Comm. Engg., 3: 5844-5848 (2014).

[8] Y. Liu, G. Zhang, Q. Li, "WDM/TDM hybrid GPON technology”, Symposium on Photonics and Optoelectronics (SOPO), 1-3 (2011).

[9] A. M. Khan, Z. Jie, Y. Khan, M. Idrees, Y. Zhao, S. Niazi, A. Husein, A. Munir, I. Ahmed and J. Liu, " A simple and cost-effective design for simultaneous transmission of point-topoint and broadcast services in WDM-PON", Int. J. Fut. Gen. Comm. Network. 6 (41-56) 2013.

[10] Y. Khan, X. Xin, A. Hussain, A. Latif, L. Bo, A. M. Khan, “ A cost effective architecture for full duplex hybrid WDM/TDM-PON using dpsk downstream and colorless re-modulated upstream ook data", Adv. Info. Sci. Services Sciences., 4: 28-35 (2013).

[11] M. I. Afridi, J. Zhang, Y. Khan, A. Ali, A. Hussain, Y. Zhao, S. Niazi, A. M. Khan, "A full duplex broadcasting enabled centralized light source WDMPON architecture", J. Comput. Info. Sys., 8: 8885-8890 (2012).

[12] C. H. Yeh, H. C. Chien and S. Chi, "Cost effective colorless rsoa-based WDM-PON with $2.5 \mathrm{gbit} / \mathrm{s}$ uplink signal", IEEE Optical Fiber Communication Conference, 1-3 (2008).

[13] A. Hussain, Y. Chong-xiu, X. Xiang-jun, Y. Quan-xin, L. Bo, A. Hussain, A. Latif, A. Munir, Y. Khan, and I. Afridi, "A novel duplex WDM-PON with DPSK modulated downstream and re-modulation of the downlink signal for OOK upstream", Optoelect. Letters, 8: 134-137 (2012).

[14] A. Hussain, X. Xiang-jun, A. Latif, A. Hussain, Y. Chong-xiu, A. Munir, Y. Khan, and M. I. Afridi, "A novel symmetric $10 \mathrm{Gbit} / \mathrm{s}$ architecture with a single feeder fiber for WDM-PON based on chirp-managed laser", Optoelect. Letters, 8: 468-472 (2012).

[15] T. Ul Islam, A. Husain, S.S. Arshraf, "10Gbps Bidirectional Transmission GPON Network Based on Single Fiber", IEEE International Conferences on Emerging Technologies (ICET), Peshawar Pakistan, (2015).
[16] L. Zhang, X. Hu, P. Cao, T. Wang, and Y. Su, "A bidirectional radio over fiber system with multiband-signal generation using one single-drive MZM", Optics Express, 19: 5196-5201 (2011). 